\title{
Intense picosecond pulsed electric fields inhibit proliferation and induce apoptosis of HeLa cells
}

\author{
MIN ZHANG ${ }^{1}$, ZHENG-AI XIONG ${ }^{1}$, WEN-JUAN CHEN ${ }^{1}$, CHENG-GUO YAO $^{2}$, \\ ZHONG-YONG ZHAO ${ }^{2}$ and YUAN-YUAN HUA ${ }^{1}$ \\ ${ }^{1}$ Department of Obstetrics and Gynecology, The Second Affiliated Hospital of Chongqing Medical University, \\ Chongqing 400010; ${ }^{2}$ State Key Laboratory of Power Transmission Equipment and System Security and New Technology, \\ Chongqing University, Chongqing 400044, P.R. China
}

Received December 16, 2012; Accepted March 28, 2013

DOI: $10.3892 / \mathrm{mmr} .2013 .1421$

\begin{abstract}
A picosecond pulsed electric field (psPEF) is a localized physical therapy for tumors that has been developed in recent years, and that may in the future be utilized as a targeted non-invasive treatment. However, there are limited studies regarding the biological effects of psPEF on cells. Electric field amplitude and pulse number are the main parameters of psPEF that influence its biological effects. In this study, we exposed HeLa cells to a psPEF with a variety of electric field amplitudes, from 100 to $600 \mathrm{kV} / \mathrm{cm}$, and various pulse numbers, from 1,000 to 3,000. An MTT assay was used to detect the growth inhibition, while flow cytometry was used to determine the occurrence of apoptosis and the cell cycle of the HeLa cells following treatment. The morphological changes during cell apoptosis were observed using transmission electron microscopy (TEM). The results demonstrated that the cell growth inhibition rate gradually increased, in correlation with the increasing electric field amplitude and pulse number, and achieved a plateau of maximum cell inhibition $12 \mathrm{~h}$ following the pulses. In addition, typical characteristics of HeLa cell apoptosis in the experimental groups were observed by TEM. The results demonstrated that the rate of apoptosis in the experimental groups was significantly elevated in comparison with the untreated group. In the treatment groups, the rate of apoptosis was greater in the higher amplitude groups than in the lower amplitude groups. The same results were obtained when the variable was the pulse number. Flow cytometric analysis indicated that the cell cycle of the HeLa cells was arrested at the G2/M phase following psPEF treatment. Overall, our results indicated that
\end{abstract}

Correspondence to: Professor Zheng-Ai Xiong, Department of Obstetrics and Gynecology, The Second Affiliated Hospital of Chongqing Medical University, 74 Linjiang Road, Central District, Chongqing 400010, P.R. China

E-mail: paperxiong@126.com

Key words: intense picosecond pulsed electric fields, apoptosis, proliferation, cell cycle, HeLa cells
psPEF inhibited cell proliferation and induced cell apoptosis, and that these effects occurred in a dose-dependent manner. In addition, the results demonstrated that the growth of the HeLa cells was arrested at the G2/M phase following treatment. This study may provide a foundation for further in vivo experiments, and for the potential clinical application of $\mathrm{psPEF}$ in the treatment of cervical cancer.

\section{Introduction}

Cervical cancer is the most common malignant tumor of the female reproductive system. Its incidence continues to increase, while the average age of onset has decreased (1). At present, the methods of treating cervical cancer are predominantly radiotherapy, platinum-based chemotherapy and surgery. Although the traditional surgical method remains the main effective approach towards treating cervical cancer, it greatly affects the sexual and reproductive functions of the patients (2). In addition, although radiation equipment is constantly improving, and chemotherapy drugs are continually being developed, radiotherapy and chemotherapy continue to cause a series of systemic side effects that result in a reduction in the quality of the patients' lives (3). Therefore, the search for a safe, effective and non-invasive treatment that can preserve fertility and decrease the effects on the sexual function of young patients is an important research direction.

Pulsed electric field (PEF) is a biomedical engineering technique for tumor therapy that has been developed in recent years. The effect of electrical pulses on the cell structure and function, and as a biological treatment, has become a focus in the biological electromagnetics field $(4,5)$. According to the different pulse durations, PEF may be classified into millisecond (ms)-, microsecond ( $\mu \mathrm{s}$ )-, nanosecond (ns)- and picosecond (ps) PEF. A large number of studies have investigated ms-, $\mu$ s- and nsPEF.

It was demonstrated that when cells are exposed to certain millisecond or microsecond pulses, a number of aqueous channels form in the cell membrane, in a process known as reversible electroporation (RE) (6). Electroporation enhances the membrane permeability significantly, which is beneficial in enabling cells to absorb drug molecules, genetic material, protein and other macromolecular material, without 
damaging the intracellular organelles, such as the nucleus and the mitochondria. Based on this feature, the electroporation technique has been used for gene transfection (7). The theory of electroporation has also been used in a new therapeutic approach to target tumors. This method, known as electrical chemotherapy (ECT), combines chemotherapy with PEF to reduce the systemic use of chemotherapy drugs and enhance the influx of chemotherapeutic agents into cells. This therapeutic method has been successfully used in various clinical therapies, including the treatment of head, neck, skin, pancreatic and liver cancer $(9,10)$. However, if the electric field strength increases beyond a certain level, irreversible electrical breakdown occurs in the cell membrane, and the cancer cells are killed directly(11), a process termed irreversible electrical breakdown (IREB). It has been demonstrated that when microsecond pulses are applied in living pork liver, these induce not only cell RE and IREB, but also cell apoptosis (12). Our previous study indicated that IREB induced by a low voltage and with a higher number of pulses ablated HeLa cells as effectively as a high voltage. The combination of a low voltage and a higher number of pulses also resulted in the desired outcome of a greater proportion of apoptosis occurring than necrosis (13). A further reduction in the pulse duration, to nanoseconds, leads to a series of cell responses, such as apoptosis, intracellular calcium release and increased gene expression, as well as DNA and chromosome damage, despite the outer membrane remaining intact (14-17). This technique is known as intracellular electromanipulation.

Although ms-, $\mu$ s- and nsPEF have numerous biological effects and clinical applications, they continue to require the use of an invasive or minimally invasive electrode array (needles or plate electrodes) to guide the puncture into the tumor tissue. In addition, each type of PEF has different features that lead to further limitations. As a result, these three types of PEF are not able to meet the requirements that necessitate a treatment that preserves fertility and minimizes the effect on the sexual function of young patients in a safe, effective and non-invasive manner.

psPEF has an ultra-wideband spectrum [almost from direct current (DC) to $\mathrm{GHz}$ ], with a high time and spatial resolution and a low signal distortion $(18,19)$. This means that there is the potential for psPEF to be transferred to target deep tissue non-invasively and precisely, although a method of achieving this transfer to the human body non-invasively has not yet been established. Chongqing University (Chongqing, China), the experimental cooperation unit for this study, has developed an ultra-wideband impulse radiating antenna (IRA), which is composed of an ellipsoid reflector and a single cone radiator. This IRA is capable of transferring energy within a specific range, converging the pulses of electromagnetic waves in the designated area and destroying the target. The radiation energy is thus highly concentrated in time and space. Based on the optical principle, the IRA may potentially be used to transfer and focus the psPEF to target deep biological tissue without trauma. This would enable psPEF to kill tumor cells, while avoiding damage to the surrounding healthy tissue. If successful, psPEF may be considered as a non-invasive treatment for tumors (20). However, a limited number of studies have investigated the biological effects induced in tumor cells by psPEF.
Apoptosis, a type of programmed cell death, is important in the normal functioning of the body; a departure from normal apoptotic mechanisms may lead to malignant tumor formation (21). We have previously studied the antitumor effects of $\mu \mathrm{sPEF}$ and nsPEF. In this study, we exposed HeLa cells to different psPEF conditions. MTT assay, flow cytometry and transmission electron microscopy (TEM) were used to detect the effects of the psPEF on HeLa cell growth inhibition, apoptosis and the cell cycle. In addition, we investigated the interrelation between the psPEF and biological effects induced in the HeLa cells, by changing the psPEF parameters. The aim of this study was to establish the parameters of psPEF that induced the killing effect on tumor cells, in order to lay a foundation for subsequent experiments in vivo and for clinical trials. As a result, a non-invasive treatment that preserves the reproductive function of young cervical cancer patients may be realized.

\section{Materials and methods}

Chemicals and reagents. RPMI-1640 medium and fetal bovine serum (FBS) were purchased from Gibco (Grand Island, NY, USA). MTT and dimethylsulfoxide (DMSO) were obtained from Sigma (St. Louis, MO, USA), and the Annexin V-fluorescein isothiocyanate (FITC) apoptosis detection kit was purchased from Nanjing KeyGen Biotech Co., Ltd. (Nanjing, China).

Cell lines and cultures. Human cervical adenocarcinoma HeLa cells were obtained from The Institute of Ultrasound Engineering in Medicine of Chongqing Medical University (Chongqing, China). The cells were cultured in RPMI-1640 medium supplemented with $10 \% \mathrm{FBS}$ and $1 \%$ penicillin-streptomycin at $37^{\circ} \mathrm{C}$ in a $5 \%$ humidified $\mathrm{CO}_{2}$ incubator. When the HeLa cells reached 70-80\% confluence, cells were subcultured or treated with psPEF.

psPEF treatment. Having been washed three times with phosphate-buffered saline (PBS), cells were combined with $0.125 \%$ trypsin-EDTA, and then centrifuged at $800 \mathrm{x}$ g for 5 min. Cells were then resuspended in fresh RPMI-1640 medium, at a concentration of $2 \times 10^{6}$ cells $/ \mathrm{ml}$. A total of $100 \mu \mathrm{l}$ cell suspension was subsequently placed into the cuvette and exposed to 800-psec pulses with a frequency of $3 \mathrm{~Hz}$, and a corresponding electric field amplitude and pulse number. Cells that were loaded into cuvettes and placed into the circuit without being pulsed were used as the normal controls. The electric field amplitude and pulse width were monitored throughout the procedures with a DP04054 oscilloscope (Tektronix, Inc., Beaverton, OR, USA).

MTT assay. There were two purposes in performing the assay: i) to establish the length of incubation time the cells required post-pulses in order to achieve a level of maximum cell inhibition; ii) to establish whether intense psPEF was capable of affecting cell viability, and, if it was capable, whether there was any correlation between electric field amplitude, pulse number and cell inhibition. For the first purpose, cells were exposed to 800-psec pulses at a frequency of $3 \mathrm{~Hz}$, a pulse number of 2,000 and different electric field amplitudes (100, 200, 300, 
400,500 and $600 \mathrm{kV} / \mathrm{cm}$ ). Following the electrical pulse treatment, HeLa cells were seeded at a density of 5,000 cells/well in 96-well plates containing $150 \mu \mathrm{l}$ RPMI-1640 medium with $10 \%$ FBS. Cells were subsequently routinely cultured for 6 , $12,24,36$ and $48 \mathrm{~h}$ in a $5 \% \mathrm{CO}_{2}$ humidified incubator at $37^{\circ} \mathrm{C}$, respectively. A normal, control and a blank group (without cells) were included. Following the corresponding culture time, $20 \mu \mathrm{l}$ MTT $(5 \mathrm{mg} / \mathrm{ml})$ was added to each well, and the cells were incubated for an additional $4 \mathrm{~h}$. The culture medium was discarded by gentle aspiration and replaced with $150 \mu \mathrm{l}$ DMSO, prior to the plates being agitated for $10 \mathrm{~min}$ to dissolve the formazan crystals. The absorbance was then measured with an ELx800 absorbance microplate reader (BioTek Instruments, Inc., Winooski, VT, USA) at a wavelength of $490 \mathrm{~nm}$. For the second purpose, the cells were divided into six groups according to electric field amplitude (100, 200, 300, 400, 500 and $600 \mathrm{kV} / \mathrm{cm}$ ), with each group being further divided into several subgroups according to pulse number $(1,000,2,000$ and 3,000$)$. The remaining parameters of each group were the same (800-psec pulses and a frequency of $3 \mathrm{~Hz}$ ). Cells of each group were treated with the corresponding psPEF. Following treatment, the cells were incubated in 96-well plates for $12 \mathrm{~h}$. The subsequent steps in the procedure corresponded to those in the MTT assay mentioned previously. This assay was performed in quintuplicate and the experiments were repeated a minimum of three times with similar results. As established from the MTT results, we selected the electric field amplitudes of 200, 400 and $600 \mathrm{kV} / \mathrm{cm}$ as the low-, middle- and high-amplitude groups in the subsequent tests.

TEM analysis. Cell morphology was observed using TEM. Following treatment with 800-psec pulses of PEF with electric field ampitudes of 200,400 and $600 \mathrm{kV} / \mathrm{cm}$, respectively, a pulse number of 2,000 and a frequency of $3 \mathrm{~Hz}$, the cells (including the untreated group) were harvested and grown in RPMI-1640 medium containing $10 \%$ FBS for $12 \mathrm{~h}$. Both floating and adherent cells were subsequently harvested and centrifuged at $800 \mathrm{x} \mathrm{g}$ for $5 \mathrm{~min}$, and then at 1,200 x g for $10 \mathrm{~min}$. The cells were fixed overnight in $0.2 \mathrm{M}$ sodium cacodylate buffer solution ( $\mathrm{pH} 7.4$ ) containing $2 \%$ glutaraldehyde at $4{ }^{\circ} \mathrm{C}$. The samples were then post-fixed in cacodylate-buffered $1 \%$ osmium tetroxide, dehydrated, and embedded in Epon 812 for ultra-thin sectioning. Following this, ultra-thin sections were stained with uranyl acetate and lead citrate, and observed with a transmission electron microscope (H-7500; Hitachi, Tokyo, Japan) at the Chongqing Medical University Cell Imaging Facility. A total of 100 cells were sampled for each group.

Flow cytometry for cell apoptosis analysis. Cell apoptosis was identified by flow cytometry with an apoptosis detection kit. Groups were divided according to electric field amplitude and pulse number, respectively. For the division by electric field amplitude, the cells were exposed to 800-psec pulses with a frequency of $3 \mathrm{~Hz}$, a pulse number of 2,000 and with various electric field amplitudes (200, 400 and $600 \mathrm{kV} / \mathrm{cm})$. For the division by pulse number, the cells were exposed to 800 -psec pulses with a frequency of $3 \mathrm{~Hz}$, a $400 \mathrm{kV} / \mathrm{cm}$ electric field amplitude and a range of pulse numbers $(1,000$, 2,000 and 3,000). Following their respective treatments, the cells, including those in the control group, were collected and seeded in 6-well plates containing $1.5 \mathrm{ml}$ RPMI-1640 medium with $10 \% \mathrm{FBS}$, and then cultured for $12 \mathrm{~h}$ in a $5 \% \mathrm{CO}_{2}$ humidified incubator at $37^{\circ} \mathrm{C}$. Following a period of $12 \mathrm{~h}$, floating and adherent cells were harvested from each well. These HeLa cells were then washed with ice-cold PBS, and resuspended at a density of $1 \times 10^{6}$ cells $/ \mathrm{ml}$. A total of $100 \mu \mathrm{l}$ cell suspension was added to the flow tube and double-stained with Annexin $\mathrm{V}$ and propidium iodide (PI). Following incubation for $15 \mathrm{~min}$ in the dark, the fluorescence in the cells was quantitatively analyzed at an emission wavelength of $530 \mathrm{~nm}$ and an excitation wavelength of $480 \mathrm{~nm}$, using a fluorescence-activated cell sorting (FACS) Vantage SE flow cytometer system (BD Biosciences, Franklin Lakes, NJ, USA).

Flow cytometry for cell cycle analysis. In this study, HeLa cells were exposed to 800-psec pulses with pulse number 2,000, various electric field amplitudes (200, 400 and $600 \mathrm{kV} / \mathrm{cm})$ and a frequency of $3 \mathrm{~Hz}$. When the electrical pulse treatment was complete, the HeLa cells, including the control group, were seeded in 6-well plates containing $1.5 \mathrm{ml}$ RPMI-1640 medium with $10 \% \mathrm{FBS}$, and then cultured for $12 \mathrm{~h}$ in a $5 \%$ $\mathrm{CO}_{2}$ humidified incubator at $37^{\circ} \mathrm{C}$. Following a period of $12 \mathrm{~h}$, floating and adherent cells were harvested from each well and centrifuged at $800 \mathrm{x} \mathrm{g}$ for $5 \mathrm{~min}$. The cells were then washed and fixed with ice-cold alcohol (75\%) for $>24 \mathrm{~h}$. Following a further two washes, cells were incubated with PBS (pH 7.4), containing RNase (5 units) and PI for $15 \mathrm{~min}$ at $37^{\circ} \mathrm{C}$. Cell cycle distribution was then measured with the FACSVantage SE flow cytometer (BD Biosciences).

Statistical analysis. SPSS 17.0 statistical software (SPSS, Inc., Chicago, IL, USA) was used for the statistical analysis. The statistical data were presented as the mean \pm standard deviation of values from three independent experiments. Comparisons between groups were performed by the student's t-test and one-way analysis of variance (ANOVA). $\mathrm{P}<0.05$ was considered to indicate a statistically significant difference.

\section{Results}

Effect of psPEF on HeLa cell viability following different culture times. Cell proliferation was determined by MTT assay. HeLa cells were processed as described in Materials and methods. The cell survival rate in normal control cells was taken as $100 \%$ viability. The percentage of cell inhibition was determined as follows: $\%$ cell inhibition $=($ absorbance of normal control cells - absorbance of treated cells)/(absorbance of normal control cells - absorbance of blank group) x 100 . The growth inhibition of HeLa cells at different culture times following various electric field amplitude treatments, as assessed by MTT assay and calculated by the previously mentioned formula, is shown in Fig. 1. In the electric field amplitude groups $(100,200,300$ and $400 \mathrm{kV} / \mathrm{cm})$, there were notable differences in the growth inhibition rates of the HeLa cells in the 12-h groups $(10.20 \pm 1.53,19.10 \pm 2.873,28.56 \pm 4.00$ and $46.20 \pm 6.93 \%$, respectively) compared with the 6-h groups $(4.50 \pm 0.63,8.90 \pm 1.36,15.21 \pm 2.28$ and $22.12 \pm 3.32 \%$, respectively) $(\mathrm{P}<0.01)$. There were also significant differences in the growth inhibition rates between the 6 -h groups $(35.23 \pm 5.28$ and $50.56 \pm 7.58 \%)$ and 12 -h groups (56.12 \pm 8.42 and $71.23 \pm 10.60 \%)$ 


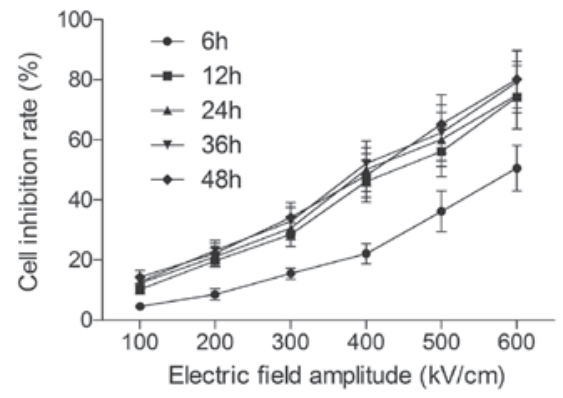

Figure 1. Effect of different culture times, following picosecond pulsed electric field (psPEF) treatment with different electric field amplitudes, on the growth inhibition of HeLa cells, measured by MTT assay. Cells were treated with psPEF with different amplitudes $(100,200,300,400,500$ and $600 \mathrm{kV} / \mathrm{cm})$ and cultured for different durations (6, 12, 24, 36 and $48 \mathrm{~h})$ following pulse treatment, respectively. Cell growth inhibition was determined by MTT assay as described in Materials and methods. Data are presented as the mean \pm standard deviation of three separate experiments.

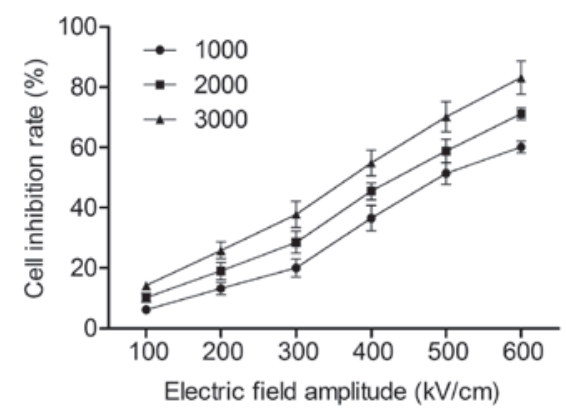

Figure 2. Effect of different electrical pulse conditions on the viability of HeLa cells, measured by MTT assay. Cells were treated with different electric field amplitudes $(100,200,300,400,500$ and $600 \mathrm{kV} / \mathrm{cm})$, and then treated with different pulse numbers $(1,000,2,000$ and 3,000) in each electric field amplitude group. Cell growth inhibition was determined by MTT assay. Data are presented as the mean \pm standard deviation of three separate experiments.

at 500 and $600 \mathrm{kV} / \mathrm{cm}$, respectively $(\mathrm{P}<0.05)$. However, there were no significant differences in the growth inhibition rates between the 12- and 24-h groups ( $\mathrm{P}>0.05)$. No significant differences were noted between the 24 - and 36 -h, or the 36 and 48 -h groups $(\mathrm{P}>0.05)$. The results demonstrated that at a given electric field amplitude, electrical pulses achieved a plateau of maximum cell inhibition $12 \mathrm{~h}$ following the pulse treatment. On the basis of these data, the cells were routinely cultured for $12 \mathrm{~h}$ following the treatment in the subsequent experiments.

Effects of different picosecond electrical pulse conditions on HeLa cell proliferation. As demonstrated in the results of the MTT assay (Fig. 2), the growth inhibition rates of the groups with a pulse number of 2,000 $(10.2 \pm 1.50,19.01 \pm 2.85$, $28.56 \pm 3.68,46.2 \pm 5.73,56.12 \pm 9.19$ and $71.23 \pm 4.48 \%$ ) were elevated in comparison with the groups with a pulse number of $1,000(6.23 \pm 0.93,13.2 \pm 1.98,20.02 \pm 3.00,36.51 \pm 5.25$, $48.02 \pm 5.32$ and $60.12 \pm 5.23 \%)(\mathrm{P}<0.05)$. Results were recorded at electric field amplitudes of $100-600 \mathrm{kV} / \mathrm{cm}$, respectively, at $100-\mathrm{kV} / \mathrm{cm}$ intervals. At a pulse number of 3,000, the growth inhibition rates in each amplitude group were 13.5 \pm 2.03 , $25.64 \pm 3.77,38.84 \pm 5.30,54.35 \pm 8.45,70.24 \pm 12.34$ and
A

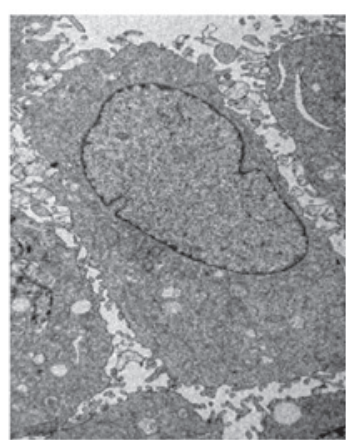

$\mathbf{B}$

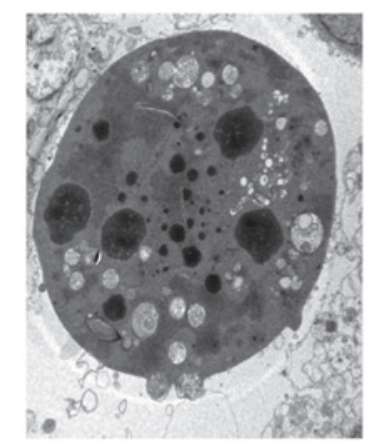

C

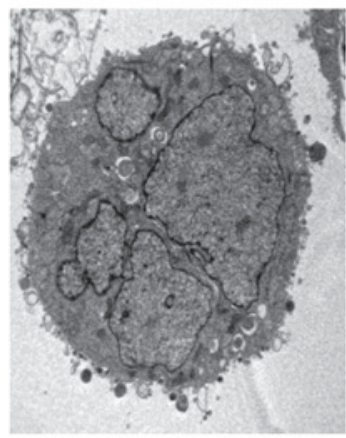

D

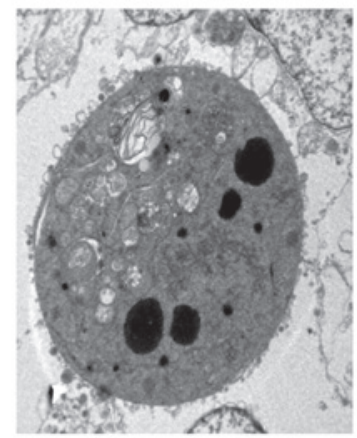

Figure 3. Cell ultrastructure of HeLa cells under transmission electron microscopy (TEM). Cells received picosecond pulsed electric field (psPEF) treatment with different electric field amplitudes (200, 400 and $600 \mathrm{kV} / \mathrm{cm})$, and were then observed with TEM. The ultrastructure of the HeLa cells: (A) without treatment with psPEF, and under an electric field amplitude of (B) $200 \mathrm{kV} / \mathrm{cm}$, (C) $400 \mathrm{kV} / \mathrm{cm}$ and (D) $600 \mathrm{kV} / \mathrm{cm}$.

$83.4 \pm 10.723 \%$, respectively. These rates were significantly higher than the results in the groups with a pulse number of $2,000(\mathrm{P}<0.05)$. The differences between the growth inhibition rates of the groups with pulse numbers of 1,000 and 2,000 were particularly notable at amplitudes of 500 and $600 \mathrm{kV} / \mathrm{cm}$ $(\mathrm{P}<0.01)$. Similarly, in each pulse number group $(1,000,2,000$ and 3,000$)$, the cell growth inhibition rate increased significantly with increasing amplitude $(\mathrm{P}<0.05)$. The differences in the growth inhibition rates were particularly of note between the $200 \mathrm{kV} / \mathrm{cm}$ groups $(13.23 \pm 1.98,19.01 \pm 2.85$ and $25.64 \pm 3.77 \%)$ and the $100 \mathrm{kV}$ groups $(6.23 \pm 0.93,10.2 \pm 1.50$, and $13.50 \pm 2.03 \%$; $\mathrm{P}<0.01)$. When the electric field amplitude was $400 \mathrm{kV} / \mathrm{cm}$, the cell growth inhibition rates increased to $36.51 \pm 5.25,46.2 \pm 5.73$ and $59.31 \pm 8.45 \%$, which were significantly higher than those in the $300 \mathrm{kV} / \mathrm{cm}$ groups $(20.02 \pm 3.005$, $28.56 \pm 3.685$ and $38.84 \pm 5.305 \%, \mathrm{P}<0.01)$. The differences between the 500 and $600 \mathrm{kV} / \mathrm{cm}$ groups were the same as the differences between the 300 and $400 \mathrm{kV} / \mathrm{cm}$ groups. In the subsequent tests, 200, 400 and $600 \mathrm{kV} / \mathrm{cm}$ were selected as the standard parameters of low-, middle- and high amplitudes.

Ultrastructural observation. TEM was used to observe the ultrastructural changes in the HeLa cells exposed to different electric field amplitudes. As demonstrated in Fig. 3, the normal HeLa cells were intact, with well-distributed chromatin and a clear nuclear membrane (Fig. 3A). However, in response to psPEF exposure at electric field amplitudes of 200, 400 and $600 \mathrm{kV} / \mathrm{cm}$, the cells became reduced in size and pyknotic, with an intact membrane, aggregated chromatin and pseudopodia-like protrusions (Figs. 3B, C and D). 

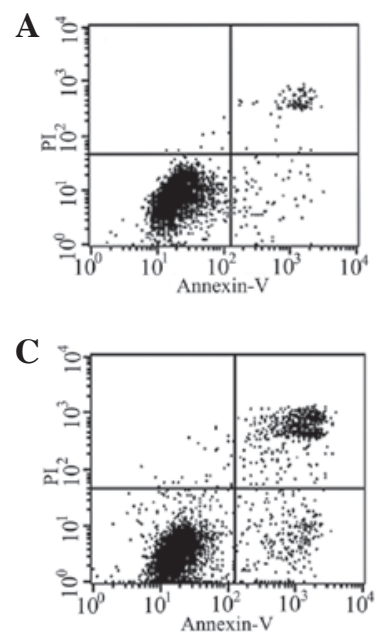
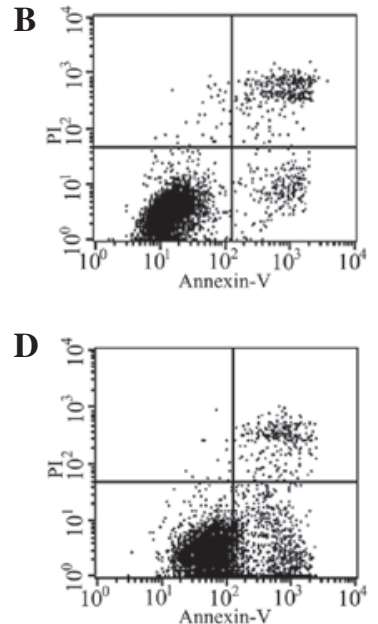

$\mathbf{E}$

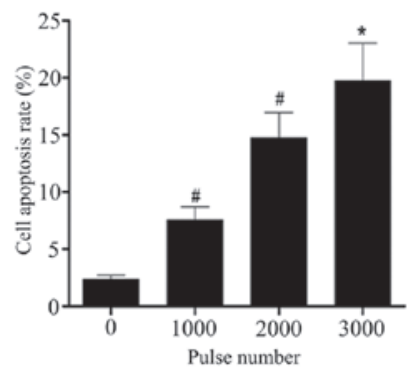

Figure 4. Apoptosis rate of HeLa cells under different pulse numbers, tested by flow cytometry. Cells were treated with different pulse numbers (1,000, 2,000 and 3,000), harvested and double stained with Annexin V and propidium iodide (PI), and then analyzed by flow cytometry. (A) Untreated group; groups with pulse numbers of (B) 1,000, (C) 2,000 and (D) 3,000; and (E) histogram plotted according to the data in A-D. Data are presented as the mean \pm standard deviation of three separate experiments. ${ }^{*} \mathrm{P}<0.05$ and ${ }^{\#} \mathrm{P}<0.01$; comparison between two neighboring groups.

A

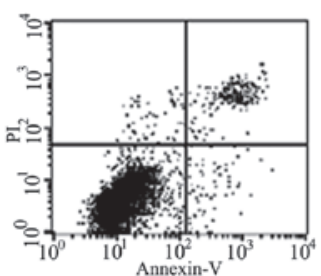

C

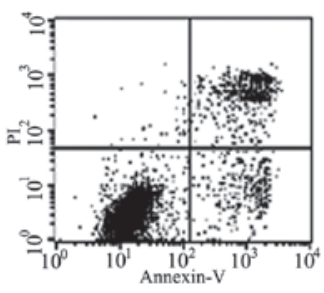

B

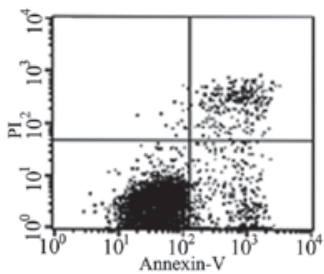

D

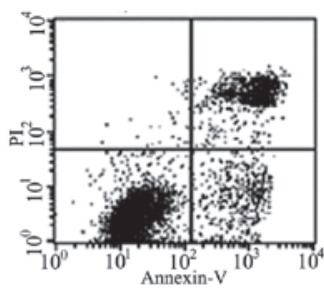

$\mathbf{E}$

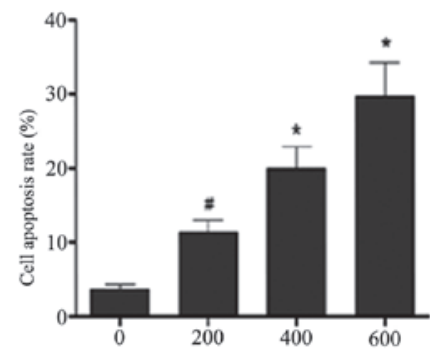

Electric field amplitude $(\mathrm{kV} / \mathrm{cm})$

Figure 5. Apoptosis rate of HeLa cells under different electric field amplitudes, tested by flow cytometry. Cells were treated with different electric field amplitudes of picosecond pulsed electric field (psPEF) (200, 400 and $600 \mathrm{kV} / \mathrm{cm})$, harvested and double stained with Annexin V-fluorescein isothiocyanate (FITC) and propidium iodide (PI), and then analyzed by flow cytometry. (A) Untreated group; groups with electric field amplitudes of (B) $200 \mathrm{kV} / \mathrm{cm}$, (C) $400 \mathrm{kV} / \mathrm{cm}$ and (D) $600 \mathrm{kV} / \mathrm{cm}$; and (E) histogram plotted according to the data in A-D. Data are presented as the mean \pm standard deviation of three separate experiments. ${ }^{*} \mathrm{P}<0.05$ and ${ }^{\#} \mathrm{P}<0.01$; comparison between two neighboring groups.

Cell apoptosis investigated by flow cytometric analysis. With the aim of assessing whether apoptosis was associated with the inhibition of proliferation induced by psPEF in HeLa cells, cell apoptosis was detected by double staining the cells with Annexin V and PI, following the electrical pulse treatment and flow cytometric analysis. As is evident in Fig. 4, the rates of apoptosis in the groups with pulse numbers of 1,000, 2,000 and 3,000 were significantly higher $(\mathrm{P}<0.05)$ than those in the the untreated group. The rate of apoptosis in the group with a pulse number of $1,000(7.55 \pm 1.13 \%)$ was significantly higher $(\mathrm{P}<0.01)$ than that in the control group $(2.35 \pm 0.35 \%)$. The difference between the groups with pulse numbers of 1,000 and 2,000 $(14.75 \pm 2.21 \%)$ was also notable $(\mathrm{P}<0.01)$. When the pulse number was increased to 3,000 , cell apoptosis increased to $19.94 \pm 2.29 \%$, which was significantly higher $(\mathrm{P}<0.05)$ than that in the group with a pulse number of 2,000 .
As shown in Fig. 5, the apoptosis rates of the 200, 400 and $600 \mathrm{kV} / \mathrm{cm}$ groups were elevated significantly $(\mathrm{P}<0.05)$, in comparison with the control group. The apoptosis rate in the $200 \mathrm{kV} / \mathrm{cm}$ group $(11.43 \pm 1.60 \%)$ was significantly higher $(\mathrm{P}<0.01)$ than that in the untreated group $(3.71 \pm 0.56 \%)$. The difference between the 200 and $400 \mathrm{kV} / \mathrm{cm}$ groups $(19.94 \pm 2.99 \%)$ was also significant $(\mathrm{P}<0.05)$. When the electric field amplitude was increased to $600 \mathrm{kV} / \mathrm{cm}$, the cell apoptosis rate reached $29.77 \pm 4.47 \%$, which was a notably higher result $(\mathrm{P}<0.05)$ than that in the $400 \mathrm{kV} / \mathrm{cm}$ group.

Effects of different electric field amplitudes on the cell cycle of HeLa cells. To determine the role of psPEF in the cell cycle progression of HeLa cells, cell cycle distribution was assessed by monitoring the intensity of PI fluorescence. As shown in Fig. 6, the ratios of G2/M phase of the cell cycle 


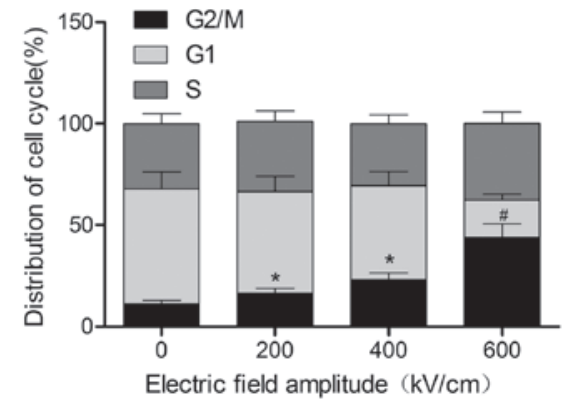

Figure 6. Flow cytometry for cell cycle analysis of Hela cells treated with various electric field amplitudes. Cells were treated with different electric field amplitudes (200, 400 and $600 \mathrm{kV} / \mathrm{cm})$, harvested and labeled with propidium iodide (PI), and then analyzed by measuring the fluorescence intensity of PI. Values are presented as the mean \pm standard deviation $(n=3)$. $P<0.05$ and ${ }^{\#} \mathrm{P}<0.01$; comparison between two neighboring groups.

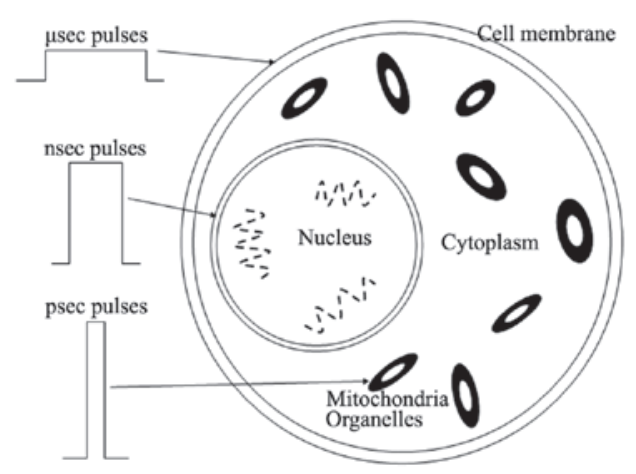

Figure 7. The simplified model of the effect on the target action point of different electrical pulses applied to the cell.

in the three experimental groups were greater than those in the untreated group $(\mathrm{P}<0.05)$. A significant difference was also observed between the $200-\mathrm{kV} / \mathrm{cm}$ group $(16.36 \pm 2.45 \%)$ and the $400-\mathrm{kV} / \mathrm{cm}$ group $(23.33 \pm 3.03 \%, \mathrm{P}<0.05)$. In addition, the proportion of cells in the $\mathrm{G} 2 / \mathrm{M}$ phase of cell cycle in the $600-\mathrm{kV} / \mathrm{cm}$ group $(44.04 \pm 6.61 \%)$ was significantly greater than in the $400-\mathrm{kV} / \mathrm{cm}$ group $(\mathrm{P}<0.01)$. As the electric field amplitude increased, the number of $\mathrm{G} 2 / \mathrm{M}$ phase cells increased significantly, while the number of cells in the G1 phase decreased gradually. This indicated that the psPEF blocked the cell cycle of HeLa cells in the G2/M phase.

\section{Discussion}

Cervical cancer is a serious threat to female health and quality of life (22). Although the late stages of cervical cancer development carry a poor prognosis, the early stages may be effectively cured with surgery. However, this results in a loss of fertility in young patients. Therefore, a treatment capable of, not only curing cervical cancer, but also preserving the fertility of young patients is necessary. As a result of widespread conventional screening, and the fact that the cervix may be fully exposed using simple methods and instruments, a number of cervical cancer patients may be diagnosed at an early stage of development, providing a suitable time for treatment with PEF.
Numerous experiments have demonstrated that PEF (6-17), from $\mathrm{msPEF}$ to $\mathrm{nsPEF}$, is capable of producing corresponding biological effects on cells. These effects have been validified by clinical experiments, although limitations for the clinical application of PEF continue to exist, as mentioned previously. It has been suggested that cell responses to different types of PEF vary due to their different spectral distributions. For example, msPEF has a long pulse duration, and therefore a lower equivalent frequency; thus, it predominantly affects cell membranes, while intracellular organelles are shielded. Its influence on the cell membrane may result in the formation of electroporation. However, the frequency of nsPEF or PEF with a shorter pulse duration is higher, which facilitates penetration of the cell membrane. This enables the nsPEF to have an impact on intracellular organelles, such as mitochondria and endoplasmic reticulum, and to induce electroporation in intracellular membranes, as well as intracellular electromanipulation $(23,24)$. Other studies have demonstrated that when pulse duration was taken as a reference point, the biological medical effects elicited differed in accordance with the changing parameters of $\operatorname{PEF}(25,26)$. As Fig. 7 shows, when the pulse duration reduces from a millisecond to a microsecond, and further to a nanosecond, the target of the PEF transfers from the cell membrane (the intracellular membrane) to the nucleus and the cytoplasm (the cytosol). A further decrease in the pulse duration, to a subnanosecond or a picosecond, changes the target action point to the nucleus and organelles, such as the mitochondria, thereby killing the cells directly. Therefore, this study focused on psPEF, with the aim of providing a foundation for the development of a non-invasive, safe and effective treatment.

In a previous study, platelets were exposed to 150-psec pulses with an electric field amplitude of $150 \mathrm{kV} / \mathrm{cm}$. The results indicated that the uptake of calcium was in a pulse number-dependent manner. Further investigation demonstrated that when B16 melanoma cells were treated with 800-psec pulses with an electric field amplitude of $950 \mathrm{kV} / \mathrm{cm}$, phosphatidylserine valgus was exhibited and caspase- 3 was activated. When the electric field amplitudes of 800-psec pulses were 550 and $490 \mathrm{kV} / \mathrm{cm}$, trypan blue staining and the determination of caspase activity indicated that there was an interrelation between the dose (pulse number) and the effect elicited (27-29). The preliminary study of this experimental team indicated that psPEF, with an electric field amplitude of $250 \mathrm{kV} / \mathrm{cm}$ and various pulse numbers $(0-50,000)$, induced apoptosis in cultured human cervical cancer cells, and that the apoptotic effect was possibly through the mitochondrial-mediated pathway (30).

At present, the pulse generator at Chongqing University is capable of generating a maximum electric field amplitude of $600 \mathrm{kV} / \mathrm{cm}$. Thus, the aim of this study was to establish the effects of psPEF with a range of electric field amplitudes $(100-600 \mathrm{kV} / \mathrm{cm})$ and a range of pulse numbers $(1,000-3,000)$, and to further observe the dose-effect correlation. Initially, investigations were undertaken to determine the culture duration required, following the pulse treatment, for psPEF to achieve a plateau of maximum cell inhibition under different electric field amplitudes. The first MTT assay result demonstrated that at a given electric field amplitude, electrical pulses achieved a plateau of maximum cell inhibition $12 \mathrm{~h}$ following the pulse treatment. Based on the experimental results, an 
MTT assay was then used to test whether psPEF was capable of inhibiting cell proliferation. The results demonstrated that psPEF had an inhibitory effect on the proliferation of the HeLa cell line in a dose (electric field amplitude and pulse number)-dependent manner. As the amplitude increased, cell growth inhibition also increased significantly, particularly at electric field amplitudes of 200, 400 and $600 \mathrm{kV} / \mathrm{cm}$, and at a pulse number of 2,000. At these specifications, the cell growth inhibition rates were markedly higher than those in the lower electric field amplitudes or pulse number groups. From the results of our preliminary experiments, 200, 400 and $600 \mathrm{kV} / \mathrm{cm}$ were chosen as the standard values for low-, middle- and high amplitudes, respectively. To investigate the biological effect induced by psPEF at these parameters of electric field amplitude, and at three typical parameters of pulse number $(1,000,2,000$ and 3,000), the flow cytometric analysis was used to determine the cell apoptosis level of each group. Under different psPEF conditions, the apoptosis of HeLa cells varied. It was apparent that the apoptosis rates in the 200-, 400- and 600-kV/cm groups were significantly higher than the rate in the untreated group. In the treatment groups, the apoptosis rate in the higher amplitude group was greater than that in the lower amplitude group. Similar results were obtained when the variable was pulse number. In addition, typical characteristics of apoptosis in the HeLa cells were observed under TEM. This indicated that intense psPEF induced apoptosis of the HeLa cells significantly in a dosedependent manner. Flow cytometric evaluation of the cell cycle demonstrated that psPEF with electric field amplitudes of 200,400 and $600 \mathrm{kV} / \mathrm{cm}$ affected the cell cycle, thereby inhibiting tumor cell growth.

This study was limited to experiments in vitro, although the next progression will be to examine experiments in vivo. This technology is currently in its infancy in gynecological diseases, and further investigation is required.

\section{Acknowledgements}

This study was supported by two grants from the National Natural Science Foundation of China (project no. 81172123) and the Health Bureau of Chongqing (project no. 2012-2-068). The authors would like to thank the members of their laboratory for their support.

\section{References}

1. Bray F, Loos AH, McCarron P, et al: Trends in cervical squamous cell carcinoma incidence in 13 European countries: changing risk and the effects of screening. Cancer Epidemiol Biomarkers Prev 14: 677-686, 2005.

2. Pecorelli S, Pasinetti B, Angioli R, Favalli G and Odicino F: Systemic therapy for gynecological neoplasms: ovary, cervix, and endometrium. Cancer Chemother Biol Response Modif 22: 515-544, 2005.

3. Green J, Kirwan J, Tierney J, et al: Concomitant chemotherapy and radiation therapy for cancer of the uterine cervix. Cochrane Database Syst Rev 3: CD002225, 2005.

4. Barnes FS and Greenebaum B (eds): Biological and medical aspects of electromagnetic fields. In: Handbook of Biological Effects of Electromagnetic Fields. 3rd edition. CRC Press, Florida, 2006.

5. Joshi RP and Schoenbach KH: Bioelectric effects of intense ultrashort pulses. Crit Rev Biomed Eng 38: 255-304, 2010.

6. Weaver JC: Electroporation: a general phenomenon for manipulating cells and tissues. J Cell Biochem 51: 426-435, 1993.
7. Mir LM: Nucleic acids electrotransfer-based gene therapy (electrogenetherapy): past, current and future. Mol Biotechnol 43: 167-176, 2009.

8. Okino M, Tomie H, Kanesada H, Marumoto M, Esato K and Suzuki H: Optimal electric conditions in electrical impulse chemotherapy. Jpn J Cancer Res 83: 1095-1101, 1992.

9. Hofmann GA, Dev SB, Dimmer S and Nanda GS: Electroporation therapy: a new approach for the treatment of head and neck cancer. IEEE Trans Biomed Eng 46: 752-759, 1999.

10. Dev SB, Rabussay DP, Widera G and Hofmann GA: Medical applications of electroporation. IEEE Trans Plasma Sci 28: 206-223, 2000.

11. Tien HT and Ottova A: The bilayer lipid membrane (BLM) under electrical fields. IEEE Trans Dielectr Electr Insul 10: 717-727, 2003.

12. Lee EW, Chen C, Prieto VE, Dry SM, Loh CT and Kee ST: Advanced hepatic ablation technique for creating complete cell death: irreversible electroporation. Radiology 255: 426-433, 2010.

13. Zhou W, Xiong Z, Liu Y, Yao C and Li C: Low voltage irreversible electroporation induced apoptosis in HeLa cells. J Cancer Res Ther 8: 80-85, 2012.

14. Stacey M, Stickley J, Fox P, Statler V, Schoenbach K, Beebe SJ and Buescher S: Differential effects in cells exposed to ultra-short, high intensity electric fields: cell survival, DNA damage, and cell cycle analysis. Mutat Res 542: 65-75, 2003

15. Katsuki S, Nomura N, Koga H, et al: Biological effects of narrow band pulsed electric fields. IEEE Trans Dielectr Electr Insul 14: 663-668, 2007.

16. Chen N, Garner AL, Chen G, et al: Nanosecond electric pulses penetrate the nucleus and enhance speckle formation. Biochem Biophys Res Commun 364: 220-225, 2007.

17. Craviso GL, Chatterjee P, Maalouf G, et al: Nanosecond electric pulse-induced increase in intracellular calcium in adrenal chromaffin cells triggers calcium-dependent catecholamine release. IEEE Trans Dielectr Electr Insul 16: 1294-1301, 2009.

18. Baum CE, Stone AP and Tyo JS (eds): Ultra-Wideband, Short-Pulse Electromagnetics 8. Springer Press, New York, 2007.

19. Bajracharya C, Shu X, Baum CE and Schoenbach KH: Target detection with impulse radiating antenna. IEEE Antennas Wireless Propag Lett 10: 496-499, 2011.

20. Long Z, Yao C, Li C, Mi Y and Sun C: Focusing properties of picosecond electric pulses in non-invasive cancer treatment. Sheng Wu Yi Xue Gong Cheng Xue Za Zhi 27: 1128-1132, 2010 (In Chinese).

21. Evan GI and Vousden KH: Proliferation, cell cycle and apoptosis in cancer. Nature 411: 342-348, 2001.

22. Jemal A, Siegel R, Ward E, Hao Y, Xu J and Thun MJ: Cancer statistics. CA Cancer J Clin 59: 225-249, 2009.

23. Beebe SJ and Schoenbach KH: Nanosecond pulsed electric fields: a new stimulus to activate intracellular signaling. J Biomed Biotechnol 2005: 297-300, 2005.

24. Schoenbach KH, Joshi RP, Kolb JF, et al: Ultrashort electrical pulses open a new gateway into biological cells. Proc IEEE 92: 1122-1137, 2004.

25. Yao C, Mo D, Li C, Sun C and Mi Y: Study of transmembrane potentials of inner and outer membranes induced by pulsed-electric-field model and simulation. IEEE Trans Plasma Sci 35: 1541-1549, 2007.

26. Yao C, Mi Y, Li C, et al: Study of transmembrane potentials on cellular inner and outer membrane - frequency response model and its filter characteristic simulation. IEEE Trans Biomed Eng 55: 1792-1799, 2008.

27. Camp JT, Shu X, Beebe SJ, Blackmore PF and Schoenbach KH: Bioelectric studies with subnanosecond pulsed electric fields. 2009 IEEE Pulsed Power Conference. June 28-July 2: pp876-879, 2009.

28. Schoenbach KH,Shu X,Joshi RP,CampJT,Heeren T,KolbJF and Beebe SJ: The effect of intense subnanosecond electrical pulses on biological cells. IEEE Trans Plasma Sci 36: 414-422, 2008.

29. Schoenbach KH, Katsuki S, Akiyama H, et al: Biological effects of intense subnanosecond electrical pulses. In: Proceedings of the Power Modulator Symposium, 2006. Conference Record of the 2006 Twenty-Seventh International. May 14-18: pp573-576, 2006.

30. Hua YY, Wang XS, Zhang Y, Yao CG, Zhang XM and Xiong ZA: Intense picosecond pulsed electric fields induce apoptosis through a mitochondrial-mediated pathway in HeLa cells. Mol Med Rep 5: 981-987, 2012. 